\title{
O PRINCÍPIO DA FLEXIBILIZAÇÃO PROCEDIMENTAL EM UMA NOVA ERA TECNOLÓGICA
}

\author{
THE PRINCIPLE OF PROCEDIMENTAL FLEXIBILIZATION IN A NEW \\ TECHNOLOGICAL AGE
}

\section{Carlos Wagner Dias Ferreira ${ }^{1}$}

\begin{abstract}
"Cada homem tem o seu momento. O sucesso e o fracasso dependem da possibilidade de cada pessoa responder ao tempo em que vive. Nem todos tiveram o tempo que mereciam; e outros, que o tiveram, não acertaram ao aproveitá-lo. Alguns tiveram virtudes que os fizeram os melhores do século, mas o bom nem sempre triunfa. Os homens e as coisas têm determinado seu instante feliz e até aos mais excelentes está determinada a sua hora.'

(Baltasar Gracián, escrito entre os anos 1626 a 1658)
\end{abstract}

\section{RESUMO}

O presente ensaio almeja analisar a viabilidade e a possibilidade de se adotar, nesses novos tempos impulsionados pela pandemia do coronavírus (Covid-19), no âmbito do processo judicial previdenciário, atos processuais instrutórios em formato digital, tais como a teleperícia e a teleaudiência, à luz do princípio processual da flexibilização procedimental instituída nos arts. 139, inciso VI, e 190 (negócio processual atípico) do Código de Processo Civil, de sorte a atender às especificidades das contingências sociais que se acham amparadas pelo direito fundamental à tutela previdenciária (arts. 201 e 203 da Constituição de 1988). Um dos desafios do processo judicial previdenciário repousa em investigar se o instituto da flexibilização procedimental pode ser utilizado nas ações previdenciárias em que o segurado ou assistido (benefício assistencial da Lei 8.742/93) aspira a concessão de prestação protetiva, especialmente em tempos de paralisia das atividades presenciais no Poder Judiciário e, como alternativa, investir na realização de teleperícias e de teleaudiências.

Palavras-chave: Processo Judicial Previdenciário. Teleperícia. Teleaudiência. Nova Era Tecnológica. Flexibilização Procedimental.

\section{ABSTRACT}

This essay aims to analyze the feasibility and the possibility of adopting, in these new times driven by the coronavirus pandemic (Covid-19), within the scope of the social security judicial process, instructional procedural acts in digital format, such as teleperience and teleaudience, in light of the procedural principle of procedural flexibilization instituted in arts. 139, item VI, and 190 (atypical procedural business) of the Civil Procedure Code, in order to meet the specificities of social contingencies that are supported by the fundamental right to social

\footnotetext{
${ }^{1}$ Juiz Federal no RN. Mestre em Direito Constitucional pela UFRN. Doutorando em Direito Público pela Universidade de Coimbra. Mestre em Direito.
} 
security protection (articles 201 and 203 of the 1988 Constitution). One of the challenges of the social security judicial process rests on investigating whether the institute of procedural flexibilization can be used in social security actions in which the insured or assisted (assistance benefit of Law 8.742 / 93) aspires to grant protective benefits, especially in times of paralysis of face-to-face activities in the Judiciary and, as an alternative, investing in teleperience and teleaudience.

Keywords: Social Security Judicial Process. Teleperience. Teleaudience. New Technological Age. Procedural Flexibilization.

\section{INTRODUÇÃO}

O futuro chegou, ao menos, no plano das tecnologias digitais ou virtuais. Aquilo que nem mesmo no mais delirante devaneio se imaginava nem sequer no futuro, agora, nestes tempos de pandemia provocada pelo novo coronavírus (Covid-19), faz parte de uma realidade que se impõe cada vez mais inexoravelmente aos mecanismos tradicionais sobre os quais se fundam o processo civil clássico e, notadamente, o campo da produção da prova.

A questão que emerge de grande importância, neste momento atual de pandemia da Covid-19, é aquilatar se o novo Código de Processo Civil (Lei 13.105/2015) ostenta ferramentas processuais adequadas e efetivas para lidar com os novos desafios criados pelas determinações das autoridades públicas e sanitárias de quarentena e isolamento social (parcial ou total), necessárias para evitar a contaminação em massa de partes, advogados, juízes, servidores e jurisdicionados em geral nas sedes físicas do Poder Judiciário, que impuseram a paralisação de atos processuais presenciais, como, por exemplo, audiências de conciliação e de instrução e julgamento e perícias judiciais.

Essa nova realidade enfrentada pelo Poder Judiciário suscitou a necessidade de garimpar, através da inovação ${ }^{2}$ tecnológica, novos modelos que pretendessem viabilizar a prática de atos processuais em ambiente digital.

O mundo já caminhava a pleno vapor rumo a uma nova onda renovatória, chamada de "Quarta Revolução Industrial”, que se notabiliza, como assinala Anita Kon (2020, p. 192) por

\footnotetext{
${ }^{2}$ Conceitua Gustavo Adolfo Pedrosa Daltro Santos (Inovação e pessoa humana. In: A quarta revolução industrial: inovação, desafios e oportunidades. Cadernos Adenauer $n^{\circ} 1$. Ano XXI. Rio de Janeiro: Fundação Konrad Adenauer, 2020, pp. 167-168) inovação como a "consequência direta da liberdade do ser humano, que não está fadado a repetir automaticamente esquemas passados, naturais ou artificiais, mas consegue colocar-se em um lugar mental relativamente independente das realidades existentes, projetando-se para além delas. A pessoa, dessa forma, consegue antecipar desejos e consequências novas, e até mesmo criar mundos alternativos (como nos gêneros literários de ficção científica e da fantasia). Tal como na poesia, o inovador consegue ir além dos significados estabelecidos das palavras e dos conceitos e trazer de algum lugar misterioso o novo, o inusitado e até o revolucionário".

${ }^{3}$ VERONESE, Alexandre. A quarta revolução industrial e blockchain: valores sociais e confiança. In: A quarta revolução industrial: inovação, desafios e oportunidades. Cadernos Adenauer, Rio de Janeiro, n. 1. ano 21, 2020. p. 64-65 explicita que o "termo 'Quarta Revolução Industrial' ganhou destaque com a sua inserção nos debates do Fórum Econômico Mundial, de Davos (Suíça) a partir de 2015-2016. Um dos fundadores do Fórum, Klauss Schwab, publicou dois livros sobre o tema. Porém, o conceito preliminar ao debate, revolução industrial, é bem mais antigo e foi incorporado no linguajar corrente, sendo - inclusive - dicionarizado, como bem lembram Yougxin Liao e outros. Segundo esses autores, o termo 'revolução industrial' tem sido usado para identificar fases amplas do uso de tecnologias nos processos produtivos. A primeira revolução industrial se refere à mecanização a vapor da produção. A segunda se refere
} 
novas tecnologias, produtos, serviços e processos de produção em todas as áreas do conhecimento e do saber em busca de fundir os ambientes físicos, digitais e biológicos, "com impactos em todas as atividades humanas, disciplinas, economias e intensamente nas indústrias e serviços".

Ao longo do tempo, o recrudescimento do processo de incremento da tecnologia digital no direito e, em particular, na ciência processual civil, com conversão dos autos físicos em eletrônicos, tem propiciado grande avanço na celeridade processual, muito mais do que meras alterações nas regras procedimentais ou mesmo a criação de novos institutos. Pode-se até arriscar a dizer que a tecnologia digital tem sido mais eficiente em minimizar os efeitos da demora na entrega da prestação jurisdicional do que as seguidas alterações promovidas nas legislações processuais no Brasil, com destaque especial para a instituição de um novo Código de Processo Civil em 2015.

A tentativa de "tecnologizar", porém, o Poder Judiciário em ritmo acelerado e intenso, sobretudo na realização de audiências e perícias por meio de videoconferência, tem acarretado problemas, dificuldades e assunção de novas responsabilidades antes inexistentes, como, por exemplo, a imperiosidade de assumir o ônus de se promover a estabilidade da plataforma digital, além de assegurar a identificação, a imagem, a privacidade e a incomunicabilidade de partes e testemunhas.

Neste sentido, almeja este estudo analisar a viabilidade e a possibilidade de se adotar, no âmbito do processo judicial previdenciário, atos processuais em formato digital, tais como a teleaudiência e a teleperícia, à luz do princípio processual da flexibilização procedimental instituída nos arts. 139, inciso VI, e 190 (negócio processual atípico) do Código de Processo Civil, de sorte a atender às especificidades das contingências sociais que se acham amparadas pelo direito fundamental à tutela previdenciária (arts. 201 e 203 da Constituição de 1988).

\section{A FLEXIBILIZAÇÃO PROCEDIMENTAL COMO PILAR FUNDAMENTAL DO PROCESSO JUDICIAL PREVIDENCIÁRIO}

Sempre se afirmou no seio doutrinário com relativa tranquilidade que o processo previdenciário apresenta características tão próprias, sobretudo em decorrência da fundamentalidade que direito material se propõe a tutelar (prestações previdenciárias), que o processo civil clássico mostrar-se-ia insuficiente e inadequado a alcançar a devida proteção jurisdicional, o que apontaria para a necessidade de se formatar e construir através da interpretação normas jurídicas particulares (regras e princípios) de natureza processual, alicerçadas essencialmente no direito constitucional ao justo processo (SAVARIS, 2012, p. 59).

Serau Junior (2010, p. 46), ao contrário do que faz Savaris (2012) nem tanto atribui a necessidade de construção de um direito processual previdenciário próprio e, portanto, mais específico do que o tradicional processo civil, à particularidade dos sujeitos processuais (sendo

à eletrificação e a terceira se refere à eletrônica. Seria possível inserir a Quarta Revolução Industrial, portanto, na atual fase de radicalização da microeletrônica, com desdobramentos para tanto para a 'Internet das Coisas', como para o uso intensivo de algoritmos e sistemas de aprendizado de máquina, em processos que são denominados como "Inteligência Artificial"', 


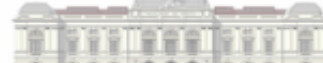

um deles, normalmente, o Instituto Nacional do Seguro Social - INSS), mas antes se assenta na especialidade do objeto litigioso a que se dedica (benefícios previdenciários).

Uma das grandes novidades trazidas pelo novo Código de Processo Civil foi a possibilidade de o juiz, na condução procedimental da demanda proposta, alterar a ordem de produção dos meios de prova, adequando-os às necessidades do conflito de modo a conferir maior efetividade à tutela do direito, sem que haja qualquer anuência das partes litigantes. Esse poder do juiz encontra-se esquadrinhado no inciso VI do art. 139 da nova Lei Instrumental Civil. A doutrina processual vem o denominando de flexibilização ou adaptabilidade procedimental.

O princípio da flexibilização procedimental não diz respeito apenas à inversão dos atos processuais que se sequenciam ao longo da marcha processual, o que consubstanciaria uma simples inversão procedimental, mas também alcança a forma como se pratica o ato processual. Afinal, prevê o art. 277 do CPC que "Quando a lei prescrever determinada forma, o juiz considerará válido o ato se, realizado de outro modo, lhe alcançar a finalidade". O que importa é se $\mathrm{o}$ ato processual atinge a sua finalidade, não ocorrendo qualquer espécie de nulidade processual. Essa previsão normativa complementa-se à perfeição à construção sistêmica do princípio da flexibilização procedimental.

$\mathrm{O}$ art. 139, inciso VI, do Código de Processo Civil, autoriza o juiz a "dilatar os prazos processuais e alterar a ordem de produção dos meios de prova, adequando-os às necessidades do conflito de modo a conferir maior efetividade à tutela do direito". Ora, quando o Código permite adequar os meios de prova às necessidades do conflito, com o objetivo de propiciar maior efetividade à proteção do direito material em disputa, é certo que também admite, por via de consequência, a modificação de como essa prova será produzida, desde que alcance a finalidade para a qual foi proposta, à luz da interpretação sistêmica que se constrói também com base no art. 277 da mesma lei processual. Esse dispositivo que confere poderes ao magistrado não se limita apenas a permitir a inversão procedimental de produção de provas, mas antes a forma como as provas serão produzidas, para que se possa concretizar o fim a que se propõe, que é o de garantir maior efetividade à tutela do direito substancial em jogo.

E esse cenário processual ganha reforço, sobretudo quando há nos dias presentes restrições de aproximação ou contato humano, dadas as regras de isolamento e distanciamento social impostas pela pandemia da Covid-19, comprometendo a tramitação de ações previdenciárias, cuja necessidade urgente de tutela jurisdicional mostra-se imprescindível. Os segurados que precisam de um auxílio de incapacidade temporária (antigo auxílio-doença) ou um benefício assistencial do deficiente ou idoso (Lei , apenas para citar alguns exemplos, não podem esperar o retorno das atividades jurisdicionais presenciais, para que só assim se retomem o curso das ações previdenciárias.

Como se sabe, na estrutura clássica do procedimento, antes chamado de ordinário, hoje, por força do novo $\mathrm{CPC}$, comum, primeiro eram praticados os atos postulatórios (da petição inicial até a eventual manifestação do autor, após a defesa do réu), que se seguiam aos atos instrutórios e, somente ao final, ter-se-iam os atos decisórios com a prolação da sentença, a pôr fim à relação jurídica processual. No entanto, já há muito que essa sistemática sequenciada de atos processuais vem sofrendo significativas mitigações, com os atos decisórios, por exemplo, 
praticamente iniciando a marcha processual, a partir de decisões interlocutórias de concessão ou denegação de tutelas de urgência.

Também se considera flexibilização procedimental a previsão encartada no art. 190, caput, do CPC, que contempla, desta feita como negócio processual (concordância das partes), a permissão de as partes estipularem mudanças no procedimento para ajustá-lo às especificidades da causa e convencionar sobre os seus ônus, poderes, faculdades e deveres processuais, antes ou durante o processo.

Muito do que vem acontecendo atualmente no Poder Judiciário quanto à realização de audiências ou perícias por videoconferência, chamadas de teleaudiências ou teleperícias, deriva de consensos celebrados entre as partes e seus respectivos advogados e o juiz, formando um verdadeiro negócio jurídico processual, de sorte a flexibilizar a forma como se desencadeiam os ônus, os poderes, as faculdades e os deveres de cada um dos participantes. Nessas audiências online por videoconferência, todos os sujeitos processuais se interligam por um computador, tablet ou smartphone com câmera, ensejando a comunicação entre si e possibilitando a realização do ato processual à distância.

Como esclarece Cueva (2016, p. 498-499), o fenômeno da flexibilização procedimental não ocorre apenas no ordenamento jurídico-processual brasileiro. Mas, antes se notabiliza no cenário internacional, como, por exemplo, na Inglaterra com o Civil Procedure Rules de 1995, que estabelece a cultura de gerenciamento de processos judiciais (case management), assim compreendido como a "possibilidade de o juiz adotar, por iniciativa própria ou mediante oitiva ou anuência das partes, dependendo do modelo normativo, procedimento mais adequado à solução do conflito levado à apreciação do Judiciário". Da mesma forma, Portugal, no art. 265-A do Código de Processo Civil, na redação alterada em 1996, e, na França, com a permissão de celebração de negócios processuais

$\mathrm{O}$ direito previdenciário, por sua vez, e, consequentemente, o direito processual previdenciário, cuida de tutelar, na esfera jurisdicional, a cobertura dos eventos de incapacidade temporária e permanente para o trabalho, idade avançada, proteção à gestante (maternidade) e ao trabalhador em situação de desemprego involuntário, salário-família e auxílio-reclusão para segurados de baixa renda e pensão por morte, em conformidade com o disposto no art. 201, incisos I a V, da Carta Política de 1988, com a dicção dada pela EC 103/2019. Sem falar nas hipóteses de deficiência e de idoso em estado de miserabilidade sob o manto protetivo da Assistência Social na forma do art. 203 da CF/88. Enfim, trata de situações de desamparo ou de quando indivíduos da sociedade estão em condições de extrema vulnerabilidade e consequente fragilidade física, mental, emocional, econômica e social.

De fato, o direito material previdenciário, como acentua Savaris (2012, p. 60), desfruta de íntima ligação com os direitos humanos fundamentais e, por isso mesmo, merecem um processo específico, diferenciado e adaptado à sua realidade concreta ${ }^{4}$.

\footnotetext{
${ }^{4}$ Savaris (2012, p. 60) ainda reforça a sua tese ressaltando que: “O direito material cuja satisfação se pretende no processo previdenciário é um bem de índole alimentar, um direito humano fundamental, um direito constitucional fundamental. Um bem jurídico previdenciário corresponde à ideia de uma prestação indispensável à manutenção do indivíduo que a persegue em juízo. Essa primeira noção é reconhecidamente basilar, mas extremamente importante: uma prestação previdenciária tem natureza alimentar; destina-se a prover recursos de subsistência digna para os beneficiários da previdência social que se encontrem nas contingências sociais definidas em lei; destina-se a suprir as necessidades primárias, vitais e presumivelmente
} 
Em julgado submetido à sistemática dos recursos repetitivos, o Superior Tribunal de Justiça, ao apreciar a questão atinente à consequência jurídico-processual da ausência ou insuficiência de prova idônea a servir de indício razoável de prova material a caracterizar a condição de segurado especial, entendeu que nesses casos não se deve julgar improcedente a pretensão autoral, porém extinguir o processo sem resolução do mérito, dada a falta de apresentação de documentos indispensáveis à propositura da ação, nos termos desenhados nos arts. 283 e 284 do Código de Processo Civil de 1973 (Arts. 320 e 321 do atual Código de Processo de 2015). O STJ, embora não tenha feito menção expressa, acolheu, a bem da verdade, no caso examinado a doutrina da coisa julgada secundum eventum probationis.

No voto do Min. Relator Napoleão Nunes Maia Filho, restou assentado que o processo judicial previdenciário ostenta particularidades que o diferenciam do processo civil tradicional, justamente em decorrência da peculiaridade do direito previdenciário cuidar, em última análise, de direitos fundamentais e, portanto, de benefícios de envergadura constitucional ${ }^{5}$.

Entretanto, a história do processo civil revela que nem sempre foi assim. Como será visto mais adiante, o procedimento foi concebido originariamente para ser uniforme e petrificado - e, portanto, insuscetível de adaptações ou flexibilizações - para todas as hipóteses do direito substancial ou material, independentemente das circunstâncias intrínsecas e extrínsecas que poderiam interferir na dinâmica do curso processual.

urgentes do segurado e às de sua família, tais como alimentação, saúde, higiene, vestuário, transporte, moradia etc. O que está em jogo em uma ação previdenciária são valores sine qua non para a sobrevivência de modo decente. É o direito de não depender da misericórdia ou auxílio de outrem. O direito à previdência social é um direito humano fundamental. Não é vão lembrar que a proteção previdenciária corresponde a um direito intimamente ligado à dignidade da pessoa humana. Ao referir a existência de normas de proteção social em Tratados Internacionais de Direitos Humanos, é curial reconhecer que nada obstante à diversidade de nações e de culturas, a preocupação com os estados de necessidade é ínsita à percepção de que a humanidade é o valor dos valores. A Seguridade Social, enquanto meio de tutela da vida humana em situações de risco de subsistência, é um instrumento de salvaguarda deste valor de singular importância".

${ }^{5}$ No seguinte trecho do voto, é possível depreender a "5. Registre-se que, tradicionalmente, o Direito Previdenciário se vale da processualística civil para regular os seus procedimentos, entretanto, não se deve perder de vista as peculiaridades das demandas previdenciárias, que justificam a flexibilização da rígida metodologia civilista. 6. Dessa forma, as normas de Direito Processual Civil devem ser aplicadas ao Processo Judicial Previdenciário levando-se em conta os cânones constitucionais atinentes à Seguridade Social, que tem como base o contexto social adverso em que se inserem os que buscam judicialmente os benefícios previdenciários. 7. Com efeito, a Constituição Federal de 1988, atenta à necessidade de proteção do trabalhador nas hipóteses de riscos sociais constitucional e legalmente eleitos, deu primazia à função social do RGPS, erigindo como direito fundamental de segunda geração o acesso à Previdência do Regime Geral. 8. Diante desse contexto, as normas previdenciárias devem ser interpretadas de modo a favorecer os valores morais da Constituição Federal/1988, que prima pela proteção do Trabalhador Segurado da Previdência Social, motivo pelo qual os pleitos previdenciários devem ser julgados no sentido de amparar a parte hipossuficiente e que, por esse motivo, possui proteção legal que lhe garante a flexibilização dos rígidos institutos processuais. Assim, deve-se procurar encontrar na hermenêutica previdenciária a solução que mais se aproxime do caráter social da Carta Magna, a fim de que as normas processuais não venham a obstar a concretude do direito fundamental à prestação previdenciária a que faz jus o segurado. 9. Aliás, assim como ocorre no Direito Penal, em que se afastam as regras da processualística civil em razão do especial garantismo conferido por suas normas ao indivíduo, deve-se dar prioridade ao princípio da busca da verdade real, diante do interesse social que envolve essas demandas. 10. não se está aqui a defender a impossibilidade de restrição de direitos fundamentais, nem a busca pela justiça social a qualquer custo, mas apenas quando juridicamente viável; sendo certo que a concessão de benefício devido configura direito subjetivo individual, que em nada desestrutura o sistema previdenciário, na medida em que não perturba o equilíbrio financeiro e atuarial dele." (STJ, RESP 1.352.721/SP, Corte Especial, j. 16/12/2015, DJe 28/04/2016). 


\section{DO PROCEDIMENTO UNIFORME AO DIREITO AO PROCEDIMENTO ADEQUADO AO CASO CONCRETO}

Na época do Estado liberal clássico, vivia-se uma atmosfera que prestigiava, no âmbito da ciência processual, o procedimento uniforme para todas as situações fáticas surgidas no campo da litigiosidade e independentemente das especificidades eventual apresentadas no direito substancial.

E isso se devia, basicamente, a dois fatores, na ótica de Marinoni, Arenhart e Mitidiero (2015, p. 25-26). O primeiro deles consistia na preocupação em garantir a liberdade e os direitos da classe burguesa. Para conservar intacta a liberdade, o Estado-juiz não poderia dar tratamento diferenciado às pessoas e aos direitos, pouco importando as qualidades dos sujeitos ou dos bens. Daí ser suficiente a tutela pecuniária, que conseguia manter íntegros os mecanismos do mercado sem afetar a sua lógica. Essa concepção liberal resultou na uniformização do procedimento e das técnicas processuais.

A segunda preocupação resultava da necessidade de manter o processo isolado em relação ao direito material. Mais especificamente no final do século XIX, a nova fase de consolidação das bases científicas do processo civil, sobretudo pela escola sistemática italiana, buscou distanciar o processo civil do direito substancial, um direito processual civil completamente descompromissado com o direito material. O procedimento único tinha o claro propósito de isolar o processo do direito material (MARINONI, ARENHART, MITIDIERO, 2015, p. 27-28).

Essa visão perdurou ainda em boa parte do século XX, porém, com Constituição de 1988, consagrou-se a ideia do direito de ação inspirado na terceira onda renovatória de acesso à justiça de Cappelletti (1988), nascendo a concepção de tutelas ou procedimentos diferenciados. O direito de ação, nesta nova fase de constitucionalização do processo, compreendia procedimentos e técnicas processuais adequadas à peculiar tutela do direito material, como sustentam Marinoni, Arenhart e Mitidiero (2015, p. 35-36).

No entanto, parece impossível o legislador instituir tantos procedimentos diferenciados quantos sejam as necessidades do direito material, dada a imprevisibilidade das situações (MARINONI, ARENHART, MITIDIERO, 2015, p. 49). Para esses casos, a Lei Instrumental Civil de 2015 trouxe a flexibilização procedimental (art. 139, VI). Dinamarco (2016, p. 429) assinala que o novo Código inaugura a oitava fase do processo civil brasileiro abrindo "o caminho para o diálogo entre todos, mediante ajustes destinados a alterar o procedimento e as situações jurídicas das partes na relação processual, segundo as concretas conveniências de cada caso", com o objetivo de evitar atos desnecessários ou estéreis e, por conseguinte, produzir resultados que sejam úteis à sociedade.

Aliás, revela Bucci (2009, p. 36) que um dos motivos da crise de eficiência do sistema de justiça civil deriva, em verdade, da irracionalidade da proliferação de ritos, exigindo que a 
diversidade das situações substanciais corresponda à multicidade de formas de tutela jurisdicional.

Assim, pode-se asseverar que a ciência processual civil navegou da época da uniformidade procedimental do século XIX, passando-se pelos procedimentos diferenciados da Constituição de 1988, chegando-se hoje com o novo Código de Processo de 2015 às normas abertas que permitem o procedimento adequado ao caso concreto.

A terceira onda renovatória de Cappelletti e Garth $(1988$, p. 71$)$ reconhece a necessidade de correlacionar e adaptar o processo civil ao tipo de litígio. Para Bedaque $(2006$, p. 45), o princípio da adequação ou adaptação ao procedimento é fundamental à correta aplicação da técnica processual.

Os modelos procedimentais e os poderes, deveres e faculdades dos sujeitos do processo devem, na medida do possível, adequar-se às peculiaridades do fenômeno jurídico material e ser compatíveis com a natureza da tutela jurisdicional pleiteada.

Como bem define Didier Jr (2015, p. 114, 117), a flexibilização procedimental, também conhecida como adaptabilidade ou elasticidade do processo, deriva do princípio da adequação, que, por sua vez, decorre do postulado constitucional do acesso à justiça ou da inafastabilidade do controle jurisdicional (art. 5, $\mathrm{XXXV}$, da $\mathrm{CF} / 88$ ), na perspectiva da tutela jurisdicional adequada (ao lado das vertentes da tutela jurisdicional efetiva e tempestiva). Consiste, em seu olhar, na permissão conferida ao juiz para, no caso concreto, "adaptar o procedimento às peculiaridades da causa que lhe é submetida", e exemplifica, como uma de suas hipóteses, o inciso VI do art. 139 do CPC, que expressamente autoriza o juiz a dilatar prazos processuais e alterar a ordem de produção de provas, para atender às particularidades do conflito ${ }^{6}$.

Para tanto, Bedaque (2006, p. 107-111) advoga a flexibilização, o incremento e a ampliação dos poderes do juiz na direção e no gerenciamento do procedimento ${ }^{7}$. Com isso, o

\footnotetext{
${ }^{6}$ Entretanto, embora defenda a flexibilidade procedimental, pondera Didier (2015, p. 119) que "A adequação jurisdicional do processo deve ser precedida de uma intimação às partes, para preservar o contraditório e respeitar o modelo cooperativo de processo. As partes não podem ser surpreendidas com mudanças do procedimento, sem que se lhes dê a chance de se adaptarem a elas, alterando, se for o caso, as suas estratégias processuais",

Bedaque (2006, p. 107-111) ensina que: “Além da simplificação da técnica - ou, pelo menos, da nãoexacerbação do formalismo estéril -, é também imprescindível dotar o juiz de poderes mais flexíveis na direção e condução do processo, possibilitando a adoção de soluções adequadas às especificidades dos problemas surgidos durante o desenvolvimento da relação processual. A tendência de reforçar os poderes do juiz, fundada no interesse público existente em todo processo, consistente na solução adequada da crise verificada no plano substancial e trazida para exame do Poder Judiciário, tem seu marco inicial na reforma do processo civil austríaco de 1896, liderada por Franz Klein. Nessa linha, entre as diversas sugestões destinadas a fazer com o processo seja realmente instrumento de justiça - não meio de que se valem os inadimplentes para protelar ainda mais a realização do direito -, interessa, aqui, examinar a simplificação da técnica processual mediante a concessão de poderes ao juiz para conduzir o porcesso de forma adequada, segundo as circunstâncias. Em primeiro lugar, é preciso abandonar a ideia de que os atos processuais devem atender rigorosamente a determinada forma previamente estabelecida, não tendo o juiz poderes para flexibilizar os rigores da lei. $\mathrm{O}$ formalismo exagerado é incompatível com a visão social do processo. Não podemos olvidar que o Estado está comprometido com a correta solução das controvérsias, não com a forma do processo. Esta constitui fato de garantia do resultado e de segurança para as partes, não pode ser objeto de culto. Quanto mais o legislador valer-se de formas abertas, sem conteúdo jurídico definido, maior será a possibilidade de o juiz adaptá-las às necessidades do caso concreto. Esse poder não se confunde com a denominada 'discricionariedade judicial', mas implica ampliação da margem de controle da técnica processual pelo julgador. $O$ reforço da autoridade judiciária e a ampliação dos poderes conferidos ao juiz para adequar as regras processuais às circunstâncias da situação litigiosa constituem orientação adotada nas modificações introduzidas no processo civil inglês em
} 
direito material estaria melhor tutelado pelas técnicas que procuram conferir procedimento adequado ao caso particular trazido à apreciação jurisdicional.

Dinamarco (2016, p. 243) preocupa-se com a eficiência e a utilidade da atividade jurisdicional em tempos de uma era marcada pelo processo civil de resultados, o que justifica a adoção de técnicas processuais adaptadas à situação específica de cada direito material trazido a juízo ${ }^{8}$, especialmente quando trata de direito fundamental prestacional (natureza social), como se revestem as proteções previdenciária e assistencial.

Como se observa, a doutrina sempre apostou que a solução para concretizar a plenitude do princípio do acesso à justiça em sua tríplice dimensão (tutela jurisdicional adequada, efetiva e tempestiva) era investir maciçamente na adoção de procedimentos mais adequados às particularidades do direito material ou mesmo alterar regras procedimentais ou criar novos institutos para incrementar a tão almejada celeridade processual. Em outras palavras, durante muitos anos, sempre se acreditou, especialmente os processualistas, que a solução para a crise de morosidade do Judiciário encontrava-se no próprio direito, ou melhor, no direito processual.

Entretanto, a mera observação do mundo fenomênico tem revelado que o que mais impactou na celeridade de tramitação das ações e processos no Poder Judiciário não foi as mudanças ocorridas no âmbito da legislação processual, mas sobretudo na adoção, cada vez mais crescente, de tecnologia digital ou virtual, a começar pela criação de processos eletrônicos e a possibilidade de utilização de automatização de atos processuais e de inteligência artificial (IA).

Será que o direito e, notadamente, o direito processual, fracassou na tentativa de otimizar a prestação da tutela jurisdicional? Um dos desafios do processo judicial previdenciário repousa em investigar se o instituto da flexibilização procedimental insculpido no art. 139, inciso VI, do novo Estatuto Processual Civil, rivaliza ou convive e se potencializa com as inovações tecnológicas, no campo das ações previdenciárias em que o segurado ou assistido (benefício assistencial da Lei 8.742/93) busca a proteção social, mormente em tempos de paralisia das atividades presenciais no Poder Judiciário.

1998. E esta deve ser a concepção da atividade desenvolvida pelo juiz no processo. Ele é um dos sujeitos da relação processual, e, nessa condição, é imprescindível que participe ativamente do contraditório, até para tornar efetivo o princípio da isonomia, em seu aspecto substancial, não sendo mais admissível a figura do juiz espectador. Afinal de contas - e esta afirmação está fundada na tendência já consolidada de publicização do processo -, a atividade judicial não se destina somente a assegurar o cumprimento da técnica e das regras formais do procedimento. Acima de tudo, o juiz deve conduzir o processo, na medida do possível, de modo a extrair dele os dados da situação do direito material necessários à solução do litígio, entregando a tutela jurisdicional ao vencedor o mais rápido possível, sem perder de vista a segurança garantida pelos princípios que compõe o devido processo constitucional. Em outras palavras, compete-lhe a direção material, e não simplesmente formal, do processo".

${ }^{8}$ Dinamarco (2016, p. 243) justifica a existência de inúmeras técnicas processuais, ao dizer que: “A diversidade de provimentos concebidos e instalados na ordem processual é um dos aspectos da técnica processual, destinando-se cada um deles a debelar uma espécie de crise jurídica mediante a oferta de solução prática adequada segundo os desígnios do direito substancial e sempre com vista a produzir resultados úteis na vida dos sujeitos. Sabido que o processo civil é institucionalmente voltado a produzir tais resultados (processo civil de resultados) e que cada uma dessas situações caracterizadas como crises jurídicas apresenta dificuldades específicas que não estão necessariamente presentes em todas, é natural que as técnicas variem e sejam diferentes os provimentos a emitir em cada uma delas. É indispensável associar cada tipo de provimento - ou cada espécie processual de tutela - às variáveis situações lamentadas e à solução que lhes destina o direito material" 


\title{
4 A TELEPERÍCIA E A TELEAUDIÊNCIA COMO EXPRESSÕES FLEXIBILIDADE PROCEDIMENTAL EM UM NOVO MUNDO TECNOLÓGICO
}

\author{
No processo judicial previdenciário, a prova e, mormente, a sua produção, talvez até
} mesmo com maior incisividade quando comparado com outros tentáculos do direito processual, como o processo judicial constitucional ou administrativo (lidam predominantemente com questões exclusivamente de direito), assumem importância cardeal na formação da convicção do julgador no momento da prolação do provimento jurisdicional.

A depender do benefício previdenciário ou assistencial pleiteado em juízo, ganham relevo determinados meios de prova mais aptos e vocacionados a desvencilhar os pontos controvertidos instaurados na fase postulatória.

A imprescindibilidade da prova (oral, pericial, inspeção judicial própria ou delegada e documental) apresenta tamanho impacto no processo judicial previdenciário que a própria Turma Nacional de Uniformização dos Juizados Especiais Federais - TNU já editou as Súmulas $6^{9}$, $14^{10}, 22^{11}, 30^{12}, 31^{13}, 34^{14}, 41^{15}, 46^{16}, 47^{17}, 63^{18}, 78^{19}, 79^{20}$ e $80^{21}$, sinalizando a necessidade de produzi-la para comprovar a presença dos requisitos a tanto exigidos para a concessão de benefícios previdenciários ou assistenciais

Basta meditar sobre a pertinência probatória que liga uma específica prestação previdenciária ou assistencial e a um dado tipo de prova. Nas ações previdenciárias em que se

9 “A certidão de casamento ou outro documento idôneo que evidencie a condição de trabalhador rural do cônjuge constitui início razoável de prova material da atividade rurícola."

10 "Para a concessão de aposentadoria rural por idade, não se exige que o início de prova material corresponda a todo o período equivalente à carência do benefício."

11 "Se a prova pericial realizada em juízo dá conta de que a incapacidade já existia na data do requerimento administrativo, esta é o termo inicial do benefício assistencial."

12 "Tratando-se de demanda previdenciária, o fato de o imóvel ser superior ao módulo rural não afasta, por si só, a qualificação de seu proprietário como segurado especial, desde que comprovada, nos autos, a sua exploração em regime de economia familiar."

13 “A anotação na CTPS decorrente de sentença trabalhista homologatória constitui início de prova material para fins previdenciários."

14 "Para fins de comprovação do tempo de labor rural, o início de prova material deve ser contemporâneo à época dos fatos a provar."

15 “A circunstância de um dos integrantes do núcleo familiar desempenhar atividade urbana não implica, por si só, a descaracterização do trabalhador rural como segurado especial, condição que deve ser analisada no caso concreto."

16 “O exercício de atividade urbana intercalada não impede a concessão de benefício previdenciário de trabalhador rural, condição que deve ser analisada no caso concreto."

17 "Uma vez reconhecida a incapacidade parcial para o trabalho, o juiz deve analisar as condições pessoais e sociais do segurado para a concessão de aposentadoria por invalidez."

18 “A comprovação de união estável para efeito de concessão de pensão por morte prescinde de início de prova material."

19 “Comprovado que o requerente de benefício é portador do vírus HIV, cabe ao julgador verificar as condições pessoais, sociais, econômicas e culturais, de forma a analisar a incapacidade em sentido amplo, em face da elevada estigmatização social da doença."

20 "Nas ações em que se postula benefício assistencial, é necessária a comprovação das condições socioeconômicas do autor por laudo de assistente social, por auto de constatação lavrado por oficial de justiça ou, sendo inviabilizados os referidos meios, por prova testemunhal."

21 "Nos pedidos de benefício de prestação continuada (LOAS), tendo em vista o advento da Lei 12.470/11, para adequada valoração dos fatores ambientais, sociais, econômicos e pessoais que impactam na participação da pessoa com deficiência na sociedade, é necessária a realização de avaliação social por assistente social ou outras providências aptas a revelar a efetiva condição vivida no meio social pelo requerente." 


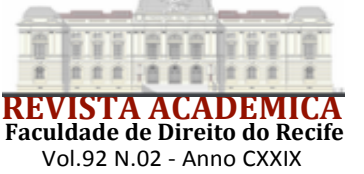

buscam benefícios previdenciários por incapacidade (auxílio por incapacidade temporária, aposentadoria por incapacidade permanente e auxílio-acidente), a rigor, a prova técnica pericial, normalmente a cargo de médico perito, afigura-se essencial para se avaliar a existência e o grau da condição incapacitante alegada. Não se pode, evidentemente, descartar a necessidade de outros meios de prova, como, por exemplo, avaliação por assistente social ou mesmo instrução processual em audiência, se o caso assim exigir.

Nesse ponto em particular, num primeiro momento, o Conselho Federal de Medicina considerou ofensa ao Código de Ética Médica e demais normativas emanadas do Conselho Federal de Medicina a conduta do médico perito judicial que utiliza recurso tecnológico sem realizar o exame físico presencial no periciando (Parecer CFM n ${ }^{\circ} 3 / 2020$ ). Na mesma linha, a Associação Brasileira de Medicina Legal e Perícias Médicas também se pronunciou.

No entanto, o Conselho Nacional de Justiça editou a Resolução n ${ }^{\circ}$ 317, de 30 de abril de 2020, estabelecendo, no art. $1^{\circ}$, que "as perícias em processos judiciais que versem sobre benefícios previdenciários por incapacidade ou assistenciais serão realizadas por meio eletrônico, sem contato físico entre perito e periciando, enquanto perdurarem os efeitos da crise ocasionada pela pandemia do novo Coronavírus".

O $\S 1^{\circ}$ do art. $1^{\circ}$ da Resolução CNJ 317/2020 resguarda que, se o perito manifestar o entendimento de que os dados constantes do prontuário médico e a entrevista por meio eletrônico com o periciando são insuficientes para formação de sua opinião técnica, o processo deverá aguardar até que seja viável a realização da perícia presencial.

O mais interessante da inovação ocorrida na seara pericial repousou sobre a diversificação de formas de realização de perícia, admitindo-se a elaboração de parecer técnico simplificado em prova técnica simplificada na forma dos arts. 464 e 472 do Código de Processo Civil (ou ainda, art. 35 da Lei 9.099/1995 e art. 12 da Lei 10.259/2001) ou de perícia fracionada, assim compreendida como aquela realizada por meio do mero exame documental e consequente confecção de parecer simplificado, posteriormente complementada com exame físico presencial.

Já, por outro lado, nas ações previdenciárias em que se pretendem o reconhecimento da qualidade de segurado especial não-contributivo (aposentadoria por idade, auxílio por incapacidade temporária, aposentadoria por incapacidade permanente, salário-maternidade, auxílio-reclusão, pensão por morte, entre outros), a prova mais adequada, inclusive por força da Súmula 149 do STJ, é aquela oral produzida em audiência instrutória ou conciliatória (art. 16, §§ $1^{\circ}$ e $2^{\circ}$, da Lei 12.153/2009), mediante a qual se toma os depoimentos das partes e das testemunhas arroladas.

Dispõe o art. $6^{\circ}$, § 3º da Resolução CNJ 314/2020, que “As audiências em primeiro grau de jurisdição por meio de videoconferência devem considerar as dificuldades de intimação de partes e testemunhas, realizando-se esses atos somente quando for possível a participação, vedada a atribuição de responsabilidade aos advogados e procuradores em providenciarem o comparecimento de partes e testemunhas a qualquer localidade fora de prédios oficiais do Poder Judiciário para participação em atos virtuais.” 


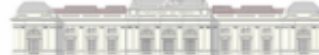

A maior dificuldade na operacionalização da audiência de conciliação (nos moldes do art. $16, \S \S 1^{\circ}$ e $2^{\circ}$, da Lei $12.153 / 2009$ ) ou de instrução e julgamento reside na preservação da incomunicabilidade de partes e das testemunhas ${ }^{22}$.

Nesta toada, o Centro Nacional de Inteligência da Justiça Federal aprovou nota técnica em que preconiza que "a testemunha envie por algum canal, a exemplo do WhatsApp, seu localizador no momento da audiência. Outro recurso interessante seria uma espécie de passeio ao vivo com a câmera pelo ambiente em que se encontra". O problema, por outro lado, pode ocorrer quando se tratar de pessoas idosas, pouca afeitas a recursos tecnológicos, necessitando, portanto, do auxílio de terceiros para manuseio da plataforma digital.

Mas, o certo é que a palavra-chave nos dias atuais de dificuldade de realização de atos presenciais deve ser a ousadia tecnológica, para que o Judiciário não pare. Aliás, de acordo com o art. $6^{\circ}$, caput e $\S 1^{\circ}$, da Resolução CNJ 314/2020, a regra é a realização remotamente de todos os atos processuais de maneira virtual ou eletrônica, de forma colaborativa com os demais órgãos do sistema de justiça, ressalvadas as hipóteses de impossibilidade técnica ou de ordem prática devidamente fundamentadas.

Ora, se, em praticamente todas as ações previdenciárias ou assistenciais, a produção jurisdicional da prova é condição quase que de procedibilidade e, portanto, fundamental, para a formação da convicção do juiz no momento da prolação de sua decisão, qual seria o óbice a produzi-la por videoconferência? Ao que tudo indica, nenhum. Longe de se constituir em algo vedado ou desaconselhável, a flexibilização procedimental, à luz do art. 139, inciso VI, do CPC, é técnica processual que se impõe nessa novo mundo de primazia da tecnologia, sendo a teleperícia e a teleaudiência suas expressões máximas.

O processo judicial previdenciário, sem dúvida alguma, é o que melhor pode se beneficiar do instituto da flexibilização procedimental, porquanto a produção de prova em juízo assume condição constitutiva do próprio reconhecimento judicial do direito à prestação previdenciária almejada. E, se a prova é tão essencial assim, por que aguardar o retorno das atividades presenciais ainda por demais incerto para, somente em seguida, produzi-la? É claro que, em todas as oportunidades de videoconferência, deve ser assegurado o contraditório e a ampla defesa - e, porque não dizer, o devido processo legal digital -, inclusive para possibilitar a oportuna impugnação, quando a tecnologia digital prejudicar a concreção do direito fundamental à proteção social.

Não se trata de procedimento especial ou diferenciado, mas de procedimento adequado a cada situação concreta. Somente a especificidade da hipótese que, no caso do direito previdenciário, recai sobre cada uma das espécies de prestações previdenciárias, definirá o procedimento a seguir, permitindo a utilização dos recursos tecnológicos da teleperícia e da teleaudiência, quando tal possibilidade mostrar-se mais adequada a propiciar a efetivação da tutela jurisdicional previdenciária.

Assim, não resta dúvida alguma de que a flexibilização procedimental convive bem com a tecnologia digital e, dessa íntima interação, pode potencializar em elevada potência o princípio do acesso à justiça em sua tríade conceitual, demonstrando que o direito e, por conseguinte, o

\footnotetext{
${ }^{22}$ No tocante às testemunhas, reza o art. 456 do $\mathrm{CPC}$, “O juiz inquirirá as testemunhas separada e sucessivamente, primeiro as do autor e depois as do réu, e providenciará para que uma não ouça o depoimento das outras"
} 
direito processual civil, pode compartilhar com a tecnologia as suas linguagens e reciprocamente contribuírem para a melhoria da performance do Poder Judiciário.

\section{CONSIDERAÇÕES FINAIS}

Diante de tudo que fora visto neste trabalho, pode-se inferir que a permissão de realização de teleperícia e de teleaudiência encontra supedâneo no princípio processual da flexibilização ou adaptabilidade procedimental, previsto nos arts. 139, inciso VI, e 190 (negócio processual atípico) do Código de Processo Civil.

Como, em praticamente todas as ações previdenciárias ou assistenciais, a produção jurisdicional da prova é condição quase que de procedibilidade e, portanto, fundamental, para a formação da convicção do juiz no momento da prolação de sua decisão, não se deve criar obstáculos à realização de atos processuais em ambiente digital, tais como a teleperícia e a teleaudiência, desencadeadas por meio de videoconferência, porquanto a flexibilização procedimental, capitulada no art. 139, inciso VI, do CPC, é técnica processual que se impõe nesses tempos de pandemia e de isolamento social compulsório, sendo a teleperícia e a teleaudiência suas expressões máximas.

O processo judicial previdenciário, sem dúvida alguma, é o que melhor pode se beneficiar do instituto da flexibilização procedimental, porquanto a produção de prova em juízo assume condição constitutiva do próprio reconhecimento judicial do direito à prestação previdenciária almejada. E, se a prova é tão essencial assim, por que aguardar o retorno das atividades presenciais ainda por demais incerto para, somente em seguida, produzi-la? É claro que, em todas as oportunidades de videoconferência, deve ser assegurado o contraditório e a ampla defesa - e, porque não dizer, o devido processo legal digital -, inclusive para possibilitar a oportuna impugnação, quando a tecnologia digital prejudicar a concreção do direito fundamental à proteção social.

Como se vê, o direito não fracassou na tentativa de otimizar a prestação da tutela jurisdicional, antes, em verdade, convive bem com a tecnologia digital e, dessa íntima interação, pode potencializar em elevada potência o princípio do acesso à justiça em sua tríade conceitual, demonstrando que o direito processual civil pode compartilhar com a tecnologia as suas linguagens e reciprocamente contribuírem para a melhoria da performance do Judiciário.

\section{REFERÊNCIAS}

BEDAQUE, José Roberto dos Santos. Efetividade do Processo e Técnica Processual. São Paulo: Malheiros, 2006.

BUCCI, Alberto. Le Noeve Riforme del Processo Civile 2009. Milano: CEDAM, 2009.

CAPPELLETTI, Mauro; GARTH, Bryant. Acesso à Justiça. Porto Alegre: Sergio Antonio Fabris Editor, 1988. 
CUEVA, Ricardo Villas Bôas. Flexibilização do Procedimento e Calendário Processual no novo CPC. In: NEGÓCIOS Processuais. Salvador: Editora Juspodivm, 2016. Coleção Grandes Temas do Novo CPC, v. 1.

DIDIER JR, Fredie. Curso de Direito Processual Civil. 17.ed. Salvador: Editora JusPODIVM, 2015. v. 1.

DINAMARCO, Cândido Rangel. Instituições de Direito Processual Civil. 8. ed. São Paulo: Malheiros, 2016. v. 1.

KOEHLER, Frederico Augusto Leopoldino (coord.). Comentários às súmulas da turma nacional de uniformização dos juizados especiais federais. Brasília: Conselho da Justiça Federal, Centro de Estudos Judiciários, 2016.

KON, Anita. O futuro do mundo do trabalho: impactos do novo paradigma tecnológico. In: A quarta revolução industrial: inovação, desafios e oportunidades. Cadernos Adenauer, Rio de Janeiro, n. 1, ano 21, 2020.

MARINONI, Luiz Guilherme; ARENHART, Sérgio Cruz; MITIDIERO, Daniel. Novo Curso de Processo Civil. São Paulo: Revista dos Tribunais, 2015. v. 3.

SANTOS, Gustavo Adolfo Pedrosa Daltro. Inovação e pessoa humana. In: A quarta revolução industrial: inovação, desafios e oportunidades. Cadernos Adenauer, Rio de Janeiro, n. 1, ano 21, 2020 .

SAVARIS, José Antonio. Direito Processual Previdenciário. 4. ed. Curitiba: Juruá Editora, 2012.

SERAU JUNIOR, Marco Aurélio. Curso de Processo Judicial Previdenciário. 3. ed. São Paulo: Editora Método, 2010.

VERONESE. Alexandre. A quarta revolução industrial e blockchain: valores sociais e confiança. In: A quarta revolução industrial: inovação, desafios e oportunidades. Cadernos Adenauer, Rio de Janeiro, n. 1, ano 21, 2020. 